\title{
Outcome of External Dacryocysto-Rhinostomy (DCR) Operation Without Silicone Tube Intubation
}

*MAH Khan ${ }^{1}$, ZI Biswas², MM Hossain ${ }^{3}$

\begin{abstract}
Background: Dacryocysto-rhinostomy (DCR) is a bypass surgery in which an anastomosis is made between the medial wall of the lacrimal sac \& the lateral wall of the nasal mucosa by cutting the intervening bone at the level of middle meatus to restore the flow of tears when the obstruction is beyond the common canaliculus. The aim of this study was to evaluate the surgical intervention of conventional external DCR without silicon tube intubation.

Methods: This study was conducted at Jahurul Islam Medical College Hospital, Kishoregonj, from July 2016 to January 2018. Fifty cases with chronic dacryocystitis were selected for the study. The operation was done under local anaesthesia. The patients were followed up for 3 months.

Result: The mean age of the patient at the time of surgery was $40.9 \pm 13.1$ years ranged from 16 to 65 years. Male to female ratio was 1:2.1. There were three patients with reactionary haemorrhage, one wound infection, two with wound gap, one epicanthal fold and one granuloma formation. There were no failed DCR in this series.
\end{abstract}

Conclusion: Conventional DCR is the most common oculoplastic surgery performed for managing epiphora due to nasolacrimal duct obstruction.

Key Words: Dacryocystitis, nasolacrimal duct obstruction, epiphora, DCR.

\section{Introduction}

Chronic dacryocystitis is a chronic inflammation of the lacrimal sac, frequently caused by bacteria due to blockage of the nasolacrimal duct leading to constant and annoying epiphora. ${ }^{1}$ This commonest external eye disease is always secondary to the obstruction in the nasolacrimal duct (NLD). Though it is not directly a blinding disorder, its complications like acute exacerbation, orbital cellulitis, corneal ulcer and even panophthalmitis may lead to blindness. Almost a century ago in 1904, a French Ophthalmologist Adeo Toti ${ }^{2}$, introduced an operation which he called Dacryocystorhinostomy (DCR) for the treatment of obstructive epiphora. It was Dupuy-Dutemps and Bourguet, in 1920-1921, who suggested that the lacrimal and nasal mucosa should be finally anastomosed to create an epitheliallined fistula. ${ }^{3}$ DCR allows tears to drain directly into the nasal cavity from the canaliculus via a new lowresistance pathway. Numerous modifications in various surgical steps of the original DCR operation has been introduced over the years for a better surgical outcome without really altering its basic concept. These procedures include conventional external DCR with or without silicon tube intubation, endoscopic DCR and endonasal DCR with Holmium or KTP Laser. ${ }^{4}$ However, external

$1 * D r$. Md. Anwar Hossain Khan, Assistant Professor, Department of Ophthalmology, Jahurul Islam Medical College Hospital, Bajitpur, Kishoregonj.

${ }^{2}$ Dr. A H M Zahirul Islam Biswas, Professor, Department of Ophthalmology, Jahurul Islam Medical College Hospital, Bajitpur, Kishoregonj.

${ }^{3}$ Dr. Md. Mosharraf Hossain, Associate Professor, Department of Ophthalmology, Jahurul Islam Medical College Hospital, Bajitpur, Kishoregonj.

*Corresponding Author

Date of submission: 20.04.2018, Date of acceptance: 15.06 .2018

AKMMC J 2018; 9(2) : 121-123 
DCR remains the gold standard for the treatment of such obstruction. ${ }^{5}$ Good outcome depends on the site of obstruction, etiology, any previous surgery and surgeon's experience. ${ }^{6}$ Success is measured by two indicators: anatomic patency of the nasolacrimal system determined by saline irrigation and functional outcome defined as resolution of epiphora.

\section{Materials and Method}

This prospective study was carried out at Jahurul Islam Medical College Hospital, Kishoregonj from July 2016 to January 2018. Total number of fifty cases with chronic dacryocystitis, both male and female were included for the study. We excluded the patients with lacrimal fistula, failed DCR and gross nasal pathology like deviated nasal septum, grossly hypertrophied inferior turbinate, atrophic rhinitis, nasal tumour, and polyp from our study. The operation was done under local anaesthesia. Nasal pack soaked with lignocaine, adrenaline and haemostatic agent is given on the same side. An incision of $2 \mathrm{~cm}$ in length, one-third of it lies above medial palpebral ligament and 8 to $10 \mathrm{~mm}$ from the medial canthus is made. The skin, orbicularis oculi muscle, and nasal periosteum with the insertion of the medial canthal tendon were dissected and retracted. The lacrimal sac is separated from medial wall and floor only. A bony osteum $12 \mathrm{~mm} \times 12 \mathrm{~mm}$ size is made by cutting frontal process of maxilla and lacrimal bone. Mucosal flap of lacrimal sac and nasal mucosa are made. Both flaps are sutured with 6-0 vicryl. Wound is closed in layer by layer. Nasal pack was removed after 24 hours. First postoperative syringing was done on $3^{\text {rd }}$ day after operation. The postoperative follow up was done at $1^{\text {st }}, 2^{\text {nd }}, 3^{\text {rd }}$ and $4^{\text {th }}$ week postoperatively. Syringing was repeated once in every month for three months to assess the patency of lacrimal system. Successful DCR was defined as clinical disappearance of epiphora. All information were documented in a predesigned proforma keeping in mind the aim of the study.

\section{Result}

In this study, out of 50 cases 16 patients (32\%) were male and 34 patients (68\%) were female, with a female to male ratio was $1: 2.1$. The patient's mean age at the time of surgery was $40.9 \pm 13.1$ years ranged from 16 to 65 years. Peak incidence of dacryocystitis was found in 41-50 years age group (Table-I). First postoperative syringing was done on $3^{\text {rd }}$ day after operation. The postoperative follow up was done at $1^{\text {st, }} 2^{\text {nd }}, 3^{\text {rd }}$ and $4^{\text {th }}$ week postoperatively. Syringing was repeated once in every month for three months to assess the patency of lacrimal system. In this study, we observed complications from external DCR are infrequent and not life threatening. There were seven patients with reactionary haemorrhage, one wound infection, three wound gaps, two epicanthal fold and one granuloma formation (Table-II). There were no failed DCR patient up to three months of observation by sac patency test (SPT).

Table-I: Age distribution of the patients $(n=50)$ :

\begin{tabular}{cc}
\hline Age in years & No. of Patients (\%) \\
\hline $10-20$ & $04(8 \%)$ \\
$21-30$ & $11(22 \%)$ \\
$31-40$ & $10(20 \%)$ \\
$41-50$ & $14(28 \%)$ \\
$51-60$ & $10(20 \%)$ \\
$61-70$ & $01(2 \%)$ \\
Total & $50(100 \%)$ \\
\hline
\end{tabular}

Table-II: Complication related to the procedure:

\begin{tabular}{lc}
\hline Complications & No. of Patients (\%) \\
\hline Reactionary hemorrhage & $03(6 \%)$ \\
Wound infection & $01(2 \%)$ \\
Wound gap & $02(4 \%)$ \\
Epicanthal fold & $01(2 \%)$ \\
Granuloma formation & $01(2 \%)$ \\
\hline
\end{tabular}

\section{Discussion}

DCR surgery has come a long way from the time of Adeo Toti but the ideal one with a low or no recurrence, minimal complications and good cosmetic is still elusive. The most common measure of success of DCR used in previous studies has been 
the anatomic patency. However, in recent years, the importance of functional outcome after DCR has been recognized as an important end point since anatomic success is not always associated with functional success. In this series, out of 50 cases 16 patients (32\%) were male and 34 patients $(68 \%)$ were female, with a male to female ratio was $1: 2.1$. The patient's mean age at the time of surgery was $40.9 \pm 13.1$ years ranged from 16 to 65 years. Peak incidence of dacryocystitis was found in 41-50 years. The lowest incidence was in the age group of 61 to 70 years age group. The study suggested that there is a relationship between age, sex and incidence of dacryocystitis. Ali MM et $a l^{7}$ also observed female predominance in their study. They found highest incidence in 30-39 years age group (38.9\%). In this study, we observed complications from DCR are infrequent and minor. There were three patients with reactionary haemorrhage, one with wound infection, two with wound gap, one epicanthal fold and one granuloma formation. These complications were managed by antibiotic and dressing. And all patients were recovered successfully. There were no failed DCR patient upto three months of observation by sac patency test. The success rate is $100 \%$ who underwent external dacryocystorhinostomy for the management of epiphora due to nasolacrimal duct obstruction. Saxena RC8 observed in his study that simple external DCR without intubation has the lowest recurrence rate and minimum complications. He published report describing external DCR without intubation as a promising technique in the treatment of chronic dacryocystitis. Besharati MR et $a l^{9}$ has reported in their study that 187 cases with chronic dacryocystitis were treated with external DCR without intubation and the success rate was $98 \%$. The complications in his study were minor like this study and included scar formation (8.6\%), wound infection $(5.3 \%)$ and granuloma formation (3.2\%).

\section{Conclusion}

Conventional DCR is the most common oculoplastic surgery performed for managing epiphora due to nasolacrimal duct obstruction. It is often considered to be a messy, laborious and non-rewarding surgery by most Ophthalmic surgeons. But it is safe and effective surgical method for the treatment of epiphora due to nasolacrimal duct obstruction.

Conflict of interest: none

\section{Reference}

1. Rather S, Singh T. Dacryocystorhinostomy with \& without silicon tube intubation in chronic dacryocystitis with nasolacrimal duct block. K K SCIENCE. 2013; 15 (1): 75-79.

2. Toti A. Nuovometodoconservatore di curaradicaledellesuppurazione chronicle del saccolacrimale (dacriocistorinostomia). Clin Moderna Firenze. 1904; 10: 385-9.

3. Alexander JF. Essential Ophthalmic Surgery. First edition. Oxford, UK: Butter- Heinmann; 2001.p.165.

4. Rahman MZ, Hossain MJ. Comparative study of success of Dacryocystorhinostomy with and without silicon tube Intubation. JAFMC Bangladesh. 2012; 8(2): 35-38.

5. Leong SC, Macewen CJ, White PS. A systematic review of outcomes after dacryocystorhinostomy in adults. Am J Rhinol Allerg. 2010; 24: 81-90.

6. Eichhorn K, Harrison AR. External vs. endonasal dacryocystorhinostomy: six of one, a half dozen of the other. Curr Opin Ophthalmol. 2010; 21: 396-403.

7. Ali MM, Israfil SM. Technology of Dacryocystorhinostomy in the National Institute of Ophthalmology and Analysis of its Results.Trans Ophthal Soc Bang. 1984; 12: 33-42.

8. Saxena RC. A few observations on Dacryocystorhinostomy in Lacrimal Fistula. Indian J Ophthal. 1972; 20: 135-5.

9. Besharati MR, Rastegar A. Results and complications of external dacryocystorhinostomy surgery at a teaching hospital in Iran. Saudi Med J. 2005; 26(12): 1940-4. 